\begin{tabular}{|c|l|}
\hline Title & $\begin{array}{l}\text { Fabrication of a micro-porous Ti-Zr alloy by electroless reduction with a calcium reductant for electrolytic capacitor } \\
\text { applications }\end{array}$ \\
\hline Author(s) & Kikuchi, Tatsuy a; Y oshida, Masumi; Taguchi, Y oshiaki; Habazaki, Hiroki; Suzuki, Ryosuke O. \\
\hline Citation & $\begin{array}{l}\text { Journal of alloys and compounds, 586, 148.154 } \\
\text { https:/doi.org/10.1016/.jallcom.2013.10.052 }\end{array}$ \\
\hline Issue Date & 2014 02-15 \\
\hline Doc URL & http:/hdl.handle.net/2115/56405 \\
\hline Type & article (author version) \\
\hline File Information & Manuscript.pdf \\
\hline
\end{tabular}

Instructions for use 


\section{Fabrication of a Micro-Porous Ti-Zr Alloy by Electroless Reduction with a Calcium Reductant for Electrolytic Capacitor Applications}

Tatsuya Kikuchi ${ }^{\mathrm{a},{ }^{*}}$, Masumi Yoshida ${ }^{\mathrm{a}}$, Yoshiaki Taguchi ${ }^{\mathrm{b}}$, Hiroki Habazaki ${ }^{\mathrm{a}}$, and Ryosuke O. Suzuki ${ }^{\mathrm{a}}$

${ }^{a}$ Faculty of Engineering, Hokkaido University

N13-W8, Kita-ku, Sapporo, Hokkaido, 060-8628, Japan

${ }^{\mathrm{b}}$ Graduate School of Chemical Science and Engineering, Hokkaido University

N13-W8, Kita-ku, Sapporo, Hokkaido, 060-8628, Japan

*Corresponding author: Tatsuya Kikuchi

TEL: +81-11-706-6340

FAX: +81-11-706-6342

E-mail:kiku@eng.hokudai.ac.jp 


\begin{abstract}
A metallic titanium and zirconium micro-porous alloy for electrolytic capacitor applications was produced by electroless reduction with a calcium reductant in calcium chloride molten salt at $1173 \mathrm{~K}$. Mixed $\mathrm{TiO}_{2}-70 \mathrm{at} \% \mathrm{ZrO}_{2}$ oxides, metallic calcium, and calcium chloride were placed in a titanium crucible and heated under argon atmosphere to reduce the oxides with the calcium reductant. A metallic Ti-Zr alloy was obtained by electroless reduction in the presence of excess calcium reductant and showed a micro-porous morphology due to the sintering of each of the reduced particles during the reduction. The residual oxygen content and surface area of the reduced Ti-Zr alloy decreased over time during the electroless reduction. The element distributions were slightly different at the positions of the alloy and were in the composition range of Ti-69.3 at $\%$ to 74.3 at\%Zr. A micro-porous Ti-Zr alloy with low oxygen content $(0.20$ $\mathrm{wt} \%)$ and large surface area $\left(0.55 \mathrm{~m}^{2} \mathrm{~g}^{-1}\right)$ was successfully fabricated by electroless reduction under optimal conditions. The reduction mechanisms of the mixed and pure oxides by the calcium reductant are also discussed.
\end{abstract}

Key words: Electrode Materials; Chemical Synthesis; Microstructure; Scanning Electron Microscopy, SEM 


\section{Introduction}

Anodic oxide films formed on valve metals such as aluminum, tantalum, and niobium, play an important role as dielectric films in electrolytic capacitors, and the electric capacitance, $\mathrm{C}$, is expressed by the following equation:

$$
\mathrm{C}=\varepsilon_{0} \varepsilon \mathrm{S} / \delta
$$

where $\varepsilon_{0}$ is the vacuum permittivity, $\varepsilon$ is the specific dielectric constant of the oxide film, $\mathrm{S}$ is the surface area of the electrode, and $\delta$ is the thickness of the oxide film. Recent developments for capacitor applications require a large $\varepsilon$-value of the oxide film, and titanium dioxide $\left(\mathrm{TiO}_{2}\right)$ has significant advantage over other oxides because $\varepsilon$-value of $\mathrm{TiO}_{2}(\varepsilon=40-135)$ is larger than those of the commonly used aluminum oxide $\left(\mathrm{Al}_{2} \mathrm{O}_{3}\right.$, $\varepsilon=9.8)$ and tantalum oxide $\left(\mathrm{Ta}_{2} \mathrm{O}_{5}, \varepsilon=27.6\right)$ [1-7]. Growth of the oxide film on titanium by anodizing, however, involves an amorphous-to-crystalline transition at low voltage, and this crystallization causes the formation of electron conductive pathways through the oxide film, enabling oxygen gas evolution on the crystalline oxides during anodizing. Therefore, titanium and its oxide are seldom applied to electrode materials for electrolytic capacitor applications.

Recently, Habazaki et al. investigated the anodizing of titanium-zirconium, molybdenum, aluminum, tungsten, and silicon alloys formed by DC magnetron sputtering [8-13]. From these investigations, they reported the formation of high capacitance composite oxide films without oxygen gas evolution during the anodizing of a Ti-62.5 at.\% $\mathrm{Zr}$ alloy $[10,12,14]$. The structure and composition of the oxide film were examined by X-ray diffraction and transmission electron microscopy, and the film formed on the alloy had nanocrystals of a monoclinic $\mathrm{ZrO}_{2}$ phase in an amorphous matrix. The capacitance of the oxide $\left(1.8 \mathrm{mF} / \mathrm{m}^{2}\right)$ was much higher than that of aluminum $\left(0.7 \mathrm{mF} / \mathrm{m}^{2}\right)$ and tantalum $\left(1.4 \mathrm{mF} / \mathrm{m}^{2}\right)$ formed under the same anodizing conditions; thus, this Ti-Zr alloy and its oxide have the potential to be electrode materials for electrolytic capacitors with high capacitance.

Titanium and zirconium are produced industrially by the Kroll process [15-18]. This process consists of three steps of operation: conversion from oxide to tetrachloride, subsequent reduction of tetrachloride to metal by liquid magnesium, and molten electrolysis of the byproduct, magnesium chloride. Sponge-like structures of metallic titanium and zirconium with low oxygen content can be commercially obtained by the Kroll process. Consequently, at least the following six processes are needed to fabricate a Ti-Zr alloy for novel electrolytic capacitor applications: a) chlorination of oxides, b) magnesium reduction, c) crushing, d) arc melting for alloying, e) sintering, and f) anodizing for oxide film formation. The Kroll process, however, is a high-cost 
batch-type production method and requires several days for the production of these metals. Therefore, a simpler technique for the production Ti-Zr alloy, without the Kroll process, must be developed to fabricate the novel Ti-Zr capacitor [19-25].

In the present investigation, the authors report a new production process for a $\mathrm{Ti}-\mathrm{Zr}$ alloy with a large surface area for Ti-Zr electrolytic capacitors. In the process, titanium and zirconium oxides are reduced at high temperature to a $\mathrm{Ti}-\mathrm{Zr}$ alloy by electroless reduction with a calcium reductant in calcium chloride molten salt. Metallic calcium can easily reduce oxide directly into metal, and many researchers have already reported the production of metals by electroless reduction with a calcium reductant [16-18, 23, 24]. Calcium chloride molten salt acts as a solvent and has a high solubility for metallic calcium and the calcium oxide formed by the electroless reduction. Direct production of the Ti-Zr alloy by calcium electroless reduction simplifies the fabrication process and reduce the price of the novel $\mathrm{Ti}-\mathrm{Zr}$ capacitor because chlorination, magnesium reduction, crushing, and arc melting are no longer needed in the production process. In addition, the reduction of micro-particles of $\mathrm{TiO}_{2}$ and $\mathrm{ZrO}_{2}$ (starting materials) is expected to form Ti-Zr micro-particles or micro-porous structures with high surface area. The aim of this investigation is to study the viability of using electroless reduction with calcium to produce well-defined Ti-Zr alloy microstructures directly from mixed oxides.

\section{Experimental}

Commercially available titanium and zirconium oxide powders (99.9 wt\%, Furuuchi Chemical Co., Japan) were used as the starting materials. The oxides, which had a composition of $\mathrm{TiO}_{2}-70$ at $\% \mathrm{ZrO}_{2}$, were mixed by wet ball-milling with zirconia balls in ethanol at $180 \mathrm{rpm}$ for $2 \mathrm{~h}[10,12]$. After milling, the starting materials and anhydrous calcium chloride (99.0 wt\%, Kojundo Chemical Laboratory Co., Japan), which was used as a molten salt, were dried in a vacuum oven at $473 \mathrm{~K}$ for several hours.

The electroless reduction of the oxides was performed as described below; Fig. 1 shows a schematic representation of the electroless reduction setup used in the present investigation. The oxide powder ( $2 \mathrm{~g})$, calcium chloride $(100 \mathrm{~g})$, and the required amount of metallic calcium (99.0 wt\%up, Hitachi Alloy, Japan) were placed in a titanium crucible (SH-632B-Ti, Sugiyama-Gen Co., Japan). The crucible was set in a SUS316L vessel, and the vessel was covered by two SUS316L plates and screws. The vessel was kept in a reaction chamber, and then the camber was heated slowly up to 873 $\mathrm{K}$ within $30 \mathrm{~min}$ under vacuum. The temperature was held for $10 \mathrm{~min}$ to remove residual moisture from the materials. After moisture removal, argon gas (1 atm) was introduced into the chamber. The temperature was gradually increased to $1173 \mathrm{~K}$ within 
$10 \mathrm{~min}$ and then held for an additional $1-20 \mathrm{~h}$ for the electroless reduction of the oxides by the calcium reductant in the calcium chloride molten salt. The electroless reduction of titanium and zirconium oxides by calcium reductant can be expressed by the following equations:

$$
\begin{aligned}
& \mathrm{TiO}_{2}+2 \mathrm{Ca}=\mathrm{Ti}+2 \mathrm{CaO} \\
& \mathrm{ZrO}_{2}+2 \mathrm{Ca}=\mathrm{Zr}+2 \mathrm{CaO}
\end{aligned}
$$

In the case of electroless reduction, the theoretical amount of calcium metal required for complete oxide reduction was defined as $\mathrm{e}=100 \%$, and the quantities of calcium metal used as the reducting agent were usually between $\mathrm{e}=100$ and $200 \%$.

After electroless reduction, the reaction chamber was cooled down to room temperature. The titanium crucible was removed from the vessel and then washed with hot water to completely dissolve the calcium chloride molten salt. The black powder obtained from the crucible was rinsed again with acetic acid, ethanol, and acetone. Finally, the materials were dried and kept in a vacuum desiccator. The electroless reduction of pure $\mathrm{ZrO}_{2}$ and $\mathrm{TiO}_{2}$ was also investigated by same experimental conditions.

The phase composition of the reduced materials was determined using X-ray diffraction analysis (XRD, XpertPro, Phillips). The residual oxygen content in the materials was quantitatively analyzed by an inert gas fusion-infrared adsorption method using an oxygen/nitrogen analyzer (TC600, LECO). Structural changes to the materials caused by electroless reduction were examined by scanning electron microscopy (SEM, Miniscope TM-1000, Hitachi) and electron probe microanalysis (EPMA, JXA-8900M ED/WD, JEOL). To observe vertical cross sections, the materials were embedded in an epoxy resin and mechanically polished. Non-conducting specimens were sputter-coated with platinum using a sputter coater (JFC-1600, JEOL) for SEM observations and coated with carbon using a coater (JEE-400, JEOL) for EPMA measurements. The specific surface area of the specimens was determined by the Brunauer, Emmett, and Teller method (BET, BELSORP-mini, BEL Japan).

\section{Results and discussion}

\subsection{Reduction of pure titanium and zirconium oxides}

The electroless reduction of zirconium oxide powder with calcium as the reductant in $\mathrm{CaCl}_{2}$ molten salt at $1173 \mathrm{~K}$ was performed to elucidate the details of the electroless reduction behavior. Fig. 2 shows X-ray diffraction patterns obtained from electrochemically reduced zirconium oxides after electroless reduction for $1 \mathrm{~h}$. Here, the amount of calcium reductant was adjusted to a) e $=100 \%$, b) $150 \%$, or c) $200 \%$. A composite oxide of calcium/zirconium (calcium zirconate, $\mathrm{CaZrO}_{3}$ ) and a lower 
zirconium oxide $\left(\mathrm{Zr}_{3} \mathrm{O}\right)$ are presented in Fig. 2a $(\mathrm{e}=100 \%)$; and the zirconium oxide powder was not reduced completely by electroless reduction under the condition. In contrast, the complete reduction of the zirconium oxide powder was observed when 50 $100 \%$ excess calcium reductant was used (Fig. $2 \mathrm{~b}$ and $2 \mathrm{c}$ ), and it was clear that a pure metallic zirconium could be produced under these experimental conditions.

The electroless reduction of zirconium oxide in the present investigation can be represented by the following electrochemical reactions:

$$
\begin{gathered}
2 \mathrm{Ca}=2 \mathrm{Ca}^{2+}+4 \mathrm{e}^{-} \quad \text { (Anodic reaction) (4) } \\
\mathrm{ZrO}_{2}+4 \mathrm{e}^{-}=\mathrm{Zr}+2 \mathrm{O}^{2-} \quad \text { (Cathodic reaction) }
\end{gathered}
$$

The entire electrochemical reaction can be expressed as equation (3). During electroless reduction, molten calcium metal (melting point: $1115 \mathrm{~K}$ ) may have floated to the surface of the molten $\mathrm{CaCl}_{2}$ at $1173 \mathrm{~K}$ because the density of molten calcium is lower than that of molten $\mathrm{CaCl}_{2}[16,26]$. The floated molten calcium metal can be easily dissolved in molten $\mathrm{CaCl}_{2}$ because the solubility is $3.9 \mathrm{~mol} \%$ calcium in $\mathrm{CaCl}_{2}$ molten salt at $1173 \mathrm{~K}$ [16]. The zirconium oxide powder at the bottom of the titanium crucible can be reduced by calcium metal dissolved in $\mathrm{CaCl}_{2}$ molten salt. A small amount of molten calcium, however, may vaporize into the SUS316L vessel during the electroless reduction because of its high vapor pressure at high temperature [26]. Therefore, electroless reduction using the calcium reductant with $\mathrm{e}=100 \%$ resulted in an incomplete reduction of the zirconium oxide powder, and a lower zirconium oxide was formed during the electroless reduction (Fig. 2a). Approximately $20 \mathrm{~mol} \%$ calcium oxide, a byproduct formed by the reduction, can be dissolved in molten $\mathrm{CaCl}_{2}$ [16], and the $\mathrm{CaO}$ formed on the materials dissolved rapidly in the molten salt. However, some of the calcium oxide will react with the residual zirconium oxide powder by the following chemical reaction:

$$
\mathrm{ZrO}_{2}+\mathrm{CaO}=\mathrm{CaZrO}_{3}
$$

Therefore, $\mathrm{Zr}_{3} \mathrm{O}$ and $\mathrm{CaZrO}_{3}$ were observed by XRD (Fig. 2a) in the incomplete reduction.

The excess calcium in the electroless reduction causes the complete reduction of zirconium oxide, which is shown in Figs. $2 b$ and $2 c$, and a pure metallic zirconium can be obtained under this condition. A small amount of calcium still remains in the molten salt after the electroless reduction. In fact, hydrogen gas evolution can be observed while washing the molten salt with hot water; the production of hydrogen gas can be expressed by the following electrochemical reaction:

$$
\mathrm{Ca}+2 \mathrm{H}_{2} \mathrm{O}=\mathrm{Ca}(\mathrm{OH})_{2}+\mathrm{H}_{2}
$$

Fig. 3a shows an SEM image of the surface of the zirconium oxide micro-particles 
used as the starting materials in the electroless reduction. It is clear that the spherical shaped 5 - $10 \mu \mathrm{m}$ secondary $\mathrm{ZrO}_{2}$ particles are agglomerations of few $100 \mathrm{~nm}$ primary $\mathrm{ZrO}_{2}$ particles. Fig. $3 \mathrm{~b}$ shows an SEM image of the material reduced by calcium with e $=100 \%$ in $\mathrm{CaCl}_{2}$ molten salt at $1173 \mathrm{~K}$ for $1 \mathrm{~h}$. Calcium zirconate with well-defined cubic microstructures (approximately $5 \mu \mathrm{m}$ in diameter) and many small particles of lower zirconium oxide (a few hundred $\mathrm{nm}$ in diameter) are observed in the SEM image and EPMA analysis. The particles and cubic structures are sintered together to form a sponge-like morphology with a cluster size range from approximately $100 \mathrm{~nm}$ to $3 \mu \mathrm{m}$ after longer electroless reduction (Figs. 3c and 3d). The appearance of these two types of morphologies after longer electroless reduction is attributable to the reduction of the zirconium oxide through intermediate compounds, cubic $\mathrm{CaZrO}_{3}$ crystals and sub-micron spherical $\mathrm{Zr}_{3} \mathrm{O}$ particles. The Pilling-Bedworth ratio ( $\mathrm{P}-\mathrm{B}$ ratio) for zirconium and its oxide is approximately 1.5 [27, 28], and the materials should shrink to 67 vol\% after electroless reduction. However, the shrinkage of the materials was not observed after electroless reduction (Fig. 3) because the reduced materials were sintered at a high temperature $(1173 \mathrm{~K})$ during the electroless reduction.

The variation of the residual oxygen content in the reduced materials, $\mathrm{C}_{\mathrm{o}}$, for different calcium stoichiometries, e, is illustrated in Fig. 4. The $\mathrm{C}_{\mathrm{o}}$ decreases rapidly with an increasing in the calcium stoichiometry, and reaches $13.4 \mathrm{wt} \%$ at $\mathrm{e}=100 \%$ because of the incomplete reduction described in Figs. 2 and 3. Metallic zirconium was produced by electroless reduction with $\mathrm{e}=150 \%$ (Fig. $2 \mathrm{~b}$ ), and the $\mathrm{C}_{\mathrm{o}}$ showed a small value of $1.33 \mathrm{wt} \%$. When a large amount of calcium reductant $(\mathrm{e}=200 \%)$ was used, zirconium particles with the lowest value of $\mathrm{C}_{\mathrm{o}}(0.16 \mathrm{wt} \%$ oxygen $)$ were successfully obtained. This suggests that the residual oxygen is also removed from the reduced zirconium particles by the dissolved calcium in the molten salt during the electroless reduction. In the metallic zirconium reduced by calcium, the oxygen dissolved in the zirconium lattice interstitially and formed a $\mathrm{Zr}-\mathrm{O}$ solid solution. A small amount of oxygen may have been captured as the byproduct $\mathrm{CaO}$, unreacted $\mathrm{ZrO}_{2}$, and composite oxide $\mathrm{CaZrO}_{3}$ in the secondary grains, although a thin native oxide film was formed on the materials after the investigations [17]. Metallic zirconium with low oxygen content can be successfully obtained by electroless reduction with a calcium reductant, and the lowest value of oxygen content is acceptable for industrial materials.

Electroless reduction of titanium dioxide powder was also performed using a calcium reductant in $\mathrm{CaCl}_{2}$ molten salt at $1173 \mathrm{~K}$ for $1 \mathrm{~h}$. A pure metallic titanium can be produced with excess calcium ( $=150-200 \%)$ in the same manner as the zirconium oxide reduction. Under these conditions, the analytical value of the oxygen 
content in the reduced titanium particles was less than $1 \mathrm{wt} \%$. From XRD measurements for phase identification, titanium dioxide was determined to have been reduced by the calcium reductant via a lower titanium oxide, $\mathrm{Ti}_{6} \mathrm{O}$.

\subsection{Fabrication of Ti-Zr alloy from mixed oxides}

Powders of $\mathrm{TiO}_{2}$ and $\mathrm{ZrO}_{2}$ with 70 at $\% \mathrm{ZrO}_{2}$ were mixed by wet ball-milling and then reduced by calcium reductant in $\mathrm{CaCl}_{2}$ molten salt at $1173 \mathrm{~K}$ to obtain Ti-70at\%Zr alloy. Fig. 5 shows X-ray diffraction patterns obtained from the mixed materials after electroless reduction with $\mathrm{e}=100-200 \%$ calcium reductant for $1 \mathrm{~h}$. In the case of the lower calcium content $\left(\mathrm{e}=100 \%\right.$ ) (Fig. 5a), the XRD pattern shows no peaks of $\mathrm{TiO}_{2}$ and $\mathrm{ZrO}_{2}$; however, lower titanium and zirconium oxides $\left(\mathrm{Ti}_{3} \mathrm{O}\right.$ and $\left.\mathrm{Zr}_{3} \mathrm{O}\right)$ were observed, as well as calcium zirconate, $\mathrm{CaZrO}_{3}$. Conversely, the materials reduced by e $=150$ and $200 \%$ were identified as metallic Ti-Zr alloy formations (Figs. 5b and c). The excess calcium reductant was also needed for the complete reduction of the oxides because of the small amount of liquid calcium that evaporated from the surface of molten salt. It is clear from Fig. 5 that the reduction behavior of the $\mathrm{TiO}_{2}$ and $\mathrm{ZrO}_{2}$ mixture was similar to the reduction behaviors described in Fig. 2 for zirconium oxide. However, the residual oxygen content in the materials reduced by $\mathrm{e}=200 \%$ calcium for $1 \mathrm{~h}$ showed a relatively high value of $1.8 \mathrm{wt} \%$ when measured by quantitative analysis, and the oxygen remained in the metallic Ti-Zr alloy after electroless reduction for $1 \mathrm{~h}$. This result strongly suggests that a longer reduction time is required to obtain a highly pure Ti-Zr alloy.

Fig. 6 shows the oxygen content in the reduced materials, $\mathrm{C}_{0}$, at different electroless reduction times, $\mathrm{t}$, in $\mathrm{CaCl}_{2}$ molten salt at $1173 \mathrm{~K}$. The oxygen content decreases rapidly as the reduction time increased during the initial period for $\mathrm{t}=2 \mathrm{~h}$, for which the oxygen content is $0.20 \mathrm{wt} \%$ oxygen. After the initial stage, the content decreases slightly with as the reduction time increased, and Ti-Zr alloy with $0.12 \mathrm{wt} \%$ oxygen was obtained by electroless reduction for $20 \mathrm{~h}$. It is clear from Fig. 6 that the longer electroless reduction resulted in an additional deoxidation from the reduced materials, which was caused by the excess calcium reductant $(\mathrm{e}=200 \%$ ).

Fig. 7 presents SEM images of the Ti-Zr alloy produced by electroless reduction with $\mathrm{e}=200 \%$ calcium reductant at the different reduction times shown in Fig. 6. All the reduced specimens showed a single phase solid solution of Ti-Zr alloy in XRD measurements. In the case of $\mathrm{t}=1 \mathrm{~h}$ (Fig. 7a), a Ti-Zr micro-porous structure with individual particle sizes of approximately $100 \mathrm{~nm}$ to $3 \mu \mathrm{m}$ was formed by electroless reduction due to the sintering of each of the nano- and micro-particles in molten salt at 
high temperature. The overall appearance was similar to that of metallic titanium and zirconium sponges reduced by the Kroll process. The particles size of the micro-porous structure increases with the reduction time (Fig. $7 \mathrm{~b}-\mathrm{d}$ ), and approximately $5-20 \mu \mathrm{m}$ diameter particles are observed at $\mathrm{t}=20 \mathrm{~h}$. Accordingly, the microstructure morphology and particle size produced when the calcium reductant was used were strongly dependent upon the electroless reduction time; and the surface area of micro-porous structure decreased as the reduction time increased.

As described in Figs. 6 and 7, the residual oxygen content in the reduced Ti-Zr alloy decreased as the electroless reduction time increased, and the surface area also decreased as the reduction time increased due to the sintering of each of the micro-particles. The large decrease in the surface area caused by sintering during the electroless reduction is unacceptable for electrolytic capacitor applications because the capacitance is proportional to the surface area of the alloy electrodes (Eq. 1). Therefore, this result suggests that Ti-Zr alloys reduced for $2 \mathrm{~h}$ (Fig. $7 \mathrm{~b}, \mathrm{C}_{0}=0.20 \mathrm{wt} \%$ ) and $4 \mathrm{~h}$ (Fig. $7 \mathrm{c}, \mathrm{C}_{0}=0.15 \mathrm{wt} \%$ ) are suitable for electrode materials, even though their residual oxygen contents are slightly higher than those of alloys produced after $20 \mathrm{~h}$ of reduction.

Fig. 8 shows a) low and b) high magnification SEM images of the vertical cross section of the reduced Ti-Zr alloy obtained by the electroless reduction with e $=200 \%$ for $2 \mathrm{~h}$ shown in Fig. 7b). The reduced materials were fixed on an electrically conductive adhesive-coated copper foil tape and then embedded in an epoxy resin and mechanically polished. A micro-porous $\mathrm{Ti}-\mathrm{Zr}$ structure with approximately $300 \mu \mathrm{m}$ diameter is obtained by electroless reduction. It is clear from Fig. 8 that the micro-porous structures consisted of 3 - $5 \mu \mathrm{m}$ spherical Ti-Zr micro-particles that were sintered together. The spaces in the micro-porous structure were completely filled by the epoxy resin, which indicated that the structure had an open, micro-porous morphology. The BET specific surface area of the micro-porous Ti-Zr alloy was determined to be $0.55 \mathrm{~m}^{2} \mathrm{~g}^{-1}$.

Fig. 9 shows the a) titanium and b) zirconium distribution obtained by EPMA analysis of the area shown in Fig. $8 \mathrm{~b}$, and the scales to the right indicate the relative intensities of titanium and zirconium. Comparing the titanium and zirconium distributions, EPMA studies showed that the elements are distributed evenly in the each of the micro-particles, although the titanium distribution is slightly different in the particles. In fact, the atomic percent of the reduced Ti-Zr alloy was determined to be Ti-69.3 at\% to 74.3 at\%Zr by 6-spot EDX measurements at different positions, and it can be observed that the micro-porous Ti-Zr alloy had few differences in concentration. 
A concentration difference, however, will be permitted for electric capacitor applications because the high capacitance of the Ti-Zr electrolytic capacitor is obtained in a composition range of Ti-50at $\%$ to $80 \mathrm{at} \% \mathrm{Zr}$ alloy $[10,12]$.

The formation behavior of a Ti-Zr micro-porous alloy by electroless reduction in $\mathrm{CaCl}_{2}$ molten salt with a $\mathrm{Ca}$ reductant at $1173 \mathrm{~K}$ is explained below. Electroless reduction of titanium and zirconium oxides is simultaneously occurred in $\mathrm{CaCl}_{2}$ molten salt by the following electrochemical reactions:

$$
\begin{aligned}
& \mathrm{TiO}_{2}+2 \mathrm{Ca}=\mathrm{Ti}+2 \mathrm{CaO} \\
& \mathrm{ZrO}_{2}+2 \mathrm{Ca}=\mathrm{Zr}+2 \mathrm{CaO}
\end{aligned}
$$

Here, these oxides are reduced to their metallic phases through lower oxides such as $\mathrm{Ti}_{2} \mathrm{O}_{3}\left(\mathrm{Zr}_{2} \mathrm{O}_{3}\right)$, $\mathrm{TiO}(\mathrm{ZrO}), \mathrm{Ti}_{2} \mathrm{O}\left(\mathrm{Zr}_{2} \mathrm{O}\right)$, and $\mathrm{Ti}_{3} \mathrm{O}\left(\mathrm{Zr}_{3} \mathrm{O}\right)[16,17,21]$. On the other hand, when $\mathrm{TiO}_{2}-\mathrm{ZrO}_{2}$ mixed oxides are kept in $\mathrm{CaCl}_{2}$ molten salt, some of the $\mathrm{ZrO}_{2}$ particles react with $\mathrm{TiO}_{2}$ by the following chemical equation:

$$
\mathrm{ZrO}_{2}+\mathrm{TiO}_{2}=\mathrm{ZrTiO}_{4}
$$

In addition, some of the $\mathrm{TiO}_{2}$ particles react with a titanium crucible during electroless reduction by the following chemical equation:

$$
3 \mathrm{TiO}_{2}+\mathrm{Ti} \text { (crucible) }=2 \mathrm{Ti}_{2} \mathrm{O}_{3}
$$

Fig. 10 shows X-ray diffraction patterns obtained from the materials before/after immersion in $\mathrm{CaCl}_{2}$ molten salt without a $\mathrm{Ca}$ reductant for $2 \mathrm{~h}$ at $1173 \mathrm{~K}$. The XRD pattern showed clearly peaks of $\mathrm{TiO}_{2}$ and $\mathrm{ZrO}_{2}$ before immersion (Fig. 10a); however, $\mathrm{ZrTiO}_{4}$ and lower titanium oxide, $\mathrm{Ti}_{2} \mathrm{O}_{3}$, were observed after immersion (Fig. 10b). The formed zirconium-titanium mixed oxide and lower titanium oxide are also reduced during electroless reduction by the following electrochemical reactions:

$$
\begin{aligned}
\mathrm{ZrTiO}_{4}+4 \mathrm{Ca} & =\mathrm{ZrTi}+4 \mathrm{CaO} \\
\mathrm{Ti}_{2} \mathrm{O}_{3}+3 \mathrm{Ca} & =2 \mathrm{Ti}+3 \mathrm{CaO}
\end{aligned}
$$

The calcium oxide formed by the electroless reduction (equations 8, 9, 12, and 13) dissolves rapidly to $\mathrm{CaCl}_{2}$ molten salt, however some of the $\mathrm{CaO}$ byproducts react with residual titanium and zirconium oxides by the following chemical reactions:

$$
\begin{aligned}
& \mathrm{TiO}_{2}+\mathrm{CaO}=\mathrm{CaTiO}_{3} \\
& \mathrm{ZrO}_{2}+\mathrm{CaO}=\mathrm{CaZrO}_{3}
\end{aligned}
$$

These calcium titanate and zirconate are also reduced to metals during electroless reduction by the following electrochemical reactions:

$$
\begin{aligned}
& \mathrm{CaTiO}_{3}+2 \mathrm{Ca}=\mathrm{Ti}+3 \mathrm{CaO} \\
& \mathrm{CaZrO}_{3}+2 \mathrm{Ca}=\mathrm{Zr}+3 \mathrm{CaO}
\end{aligned}
$$

A Ti-Zr micro-porous alloy is formed by the electroless reduction in the initial stage due to the sintering of titanium and zirconium in $\mathrm{CaCl}_{2}$ molten salt at $1173 \mathrm{~K}$ (Fig. 7a). The 
sintering behavior may be strongly affected by the chemicals (i. e. oxides, lower oxides, calcium titanate/zirconate, and metals) and its amount during electroless reduction.

In summary, this paper reports the successful fabrication of a Ti-Zr micro-porous alloy via electroless reduction of $\mathrm{TiO}_{2}-\mathrm{ZrO}_{2}$ mixed oxides by an excess amount of calcium reductant in $\mathrm{CaCl}_{2}$ molten salt at $1173 \mathrm{~K}$. A successive reduction of these oxides can be realized by the Ono-Suzuki process (OS process), which continuously produced calcium reductant at the anode by the electrolysis of calcium chloride and calcium oxide molten salt $[16,24]$. The $\mathrm{Ti}-\mathrm{Zr}$ porous alloy produced in this investigation can be used as the electrode material for a novel electrolytic capacitor with high capacitance. For such an application, the effects of the residual oxygen content and other impurities on the anodic oxide film formation should be further investigated.

\section{Conclusions}

In this investigation, titanium dioxide and zirconium oxide were reduced by a calcium reductant in calcium chloride molten salt at $1173 \mathrm{~K}$. The effects of the electroless reduction time and the amount of calcium reductant were investigated to optimize the reduction conditions. A pure metallic zirconium was obtained by electroless reduction for $1 \mathrm{~h}$ with $50-100 \%$ excess of calcium reductant over the theoretical amount; this reduction occurred via lower and composite oxides. Electroless reduction of the $\mathrm{TiO}_{2}-70 \mathrm{at} \% \mathrm{ZrO}_{2}$ mixed oxide resulted in the formation of a micro-porous Ti-Zr alloy, and the residual oxygen content and surface area of the reduced Ti-Zr alloy decreased as the electroless reduction time increased. The alloy, which had a low oxygen content $(0.20 \mathrm{wt} \%)$ and a large surface area $\left(0.55 \mathrm{~m}^{2} \mathrm{~g}^{-1}\right)$, was successfully obtained under optimal conditions and had a slightly variable chemical composition in the range of Ti- 69.3 at $\%$ to $74.3 \mathrm{at} \% \mathrm{Zr}$.

\section{Acknowledgements}

The authors would like to thank Mr. Nobuyuki Miyazaki (Hokkaido University) for his assistance with the EPMA analysis. This work was financially supported by the Japan Society for the Promotion of Science (JSPS) "KAKENHI".

\section{References}

1) K. Watanabe, M. Sakairi, H. Takahashi, S. Hirai, S. Yamaguchi, J. Electroanal. Chem. 473 (1999) 250-255.

2) K. Watanabe, M. Sakairi, H. Takahashi, K. Takahiro, S. Hirai, J. Electrochem. Soc. 148 (2001) B473-B481. 
3) Q. Li, S. Mato, P. Skeldon, G. E. Thompson, D. Masheder, H. Habazaki, K. Shimizu, Electrochim. Acta 47 (2002) 2761-2767.

4) M. Sunada, H. Takahashi, T. Kikuchi, M. Sakairi, S. Hirai, J. Solid State Electrochem. 11 (2007) 1375-1384.

5) S. Koyama, T. Kikuchi, M. Sakairi, H. Takahashi, S. Nagata, Electrochemistry 75 (2007) 573-575.

6) H. Habazaki, T. Ogasawara, K. Fushimi, K. Shimizu, S. Nagata, T. Izumi, P. Skeldon, G. E. Thompson, Electrochim. Acta 53 (2008) 8203-8210.

7) H. Habazaki, M. Yamasaki, T. Ogasawara, K. Fushimi, H. Konno, K. Shimizu, T. Izumi, R. Matsuoka, P. Skeldon, G. E. Thompson, Thin Solid Films 516 (2008) 991-998.

8) H. Habazaki, K. Takahiro, S. Yamaguchi, K. Shimizu, P. Skeldon, G. E. Thompson, G. C. Wood, Philos. Mag. A 78 (1998) 171.

9) H. Habazaki, K. Shimizu, S. Nagata, P. Skeldon, G. E. Thompson, G. C. Wood, Corr. Sci. 44 (2002) 1047-1055.

10) H. Habazaki, M. Uozumi, H. Konno, K. Shimizu, S. Nagata, K. Asami, K. Matsumoto, K. Takayama, Y. Oda, P. Skeldon, G. E. Thompson, Electrochim. Acta 48 (2003) 3257-3266.

11) H. Habazaki, M. Uozumi, H. Konno, S. Nagata, K. Shimizu, Surf. Coat. Technol. 169-170 (2003) 151-154.

12) H. Habazaki, K. Shimizu, S. Nagata, K. Asami, K. Takayama, Y. Oda, P. Skeldon, G. E. Thompson, Thin Solid Films 479 (2005) 144-151.

13) H. Habazaki, M. Uozumi, H. Konno, K. Shimizu, S. Nagata, K. Takayama, Y. Oda, P. Skeldon, G. E. Thompson, J. Electrochem. Soc 152 (2005) B263-B270.

14) H. Habazaki, H. Konno, K. Shimizu, J. Surf. Fin. Soc. Jpn. 54 (2003) 456-461.

15) T. H. Okabe, T. Oda, Y. Mitsuda, J. Alloys Compd. 364 (2004) 156-163.

16) R. O. Suzuki, J. Phys. Chem. Solids, 66 (2005) 461-465.

17) A. M. Abdelkader, E. El-Kashif, ISIJ Int. 47 (2007) 25-31.

18) A. M. Abdelkader, A Daher, J. Alloys Compd. 469 (2009) 571-575.

19) Z. Chen, D. J. Fray, W. W. Farthing, Nature 407 (2000) 361-364.

20) C. Schwandt, D. J. Fray, Electrochim. Acta 51 (2005) 66-76.

21) Il Park, T. Abiko, T. H. Okabe, J. Phys. Chem. Solids, 66 (2005) 410-413.

22) C. Schwandt, D. T. L. Alexander, D. J. Fray, Electrochim. Acta 54 (2009) 3819-3829.

23) S. Osaki, H. Sakai, R. O. Suzuki, J. Electrochem. Soc. 157 (2010) E117-E121.

24) R. F. Descallar-Arriesgado, N. Kobatashi, T. Kikuchi, R. O. Suzuki, Electrochim. 
Acta 56 (2011) 8422-8429.

25) A. M. Abdelkader, D. J. Fray, Electrochim. Acta 64 (2012) 10-16.

26) M. Baba, Y. Ono, R. O. Suzuki, J. Phys. Chem. Solids, 66 (2005) 466-470.

27) D. L. Douglass, Corr. Sci. 5 (1965) 255-262.

28) C. Proff, S. Abolhassani, C. Lemaignan, J. Nucl. Mater. 432 (2013) 222-238. 


\section{Captions}

Fig. 1 Schematic representation of the experimental apparatus for the electroless reduction of titanium and zirconium oxides by a calcium reductant.

Fig. 2 X-ray diffraction patterns of electrochemically reduced zirconium oxides after electroless reduction with a calcium reductant in $\mathrm{CaCl}_{2}$ molten salt at $1173 \mathrm{~K}$ for $1 \mathrm{~h}$. The starting materials are pure zirconium oxide powder and calcium reductant. The amounts of calcium reductant used are a) $100 \%$ (theoretical amount for complete $\mathrm{ZrO}_{2}$ reduction), b) $150 \%$ (50\% excess calcium), and c) $200 \%$ (100\% excess calcium).

Fig. 3 SEM images of a) zirconium oxide powder used as the starting materials and the materials reduced by the calcium reductant with e values of b) $100 \%$, c) $150 \%$, and d) $200 \%$ in $\mathrm{CaCl}_{2}$ molten salt at $1173 \mathrm{~K}$ for $1 \mathrm{~h}$.

Fig. 4 Change in the residual oxygen content of reduced materials, $\mathrm{C}_{0}$, with calcium stoichiometry, e, after electroless reduction in $\mathrm{CaCl}_{2}$ molten salt at $1173 \mathrm{~K}$ for $1 \mathrm{~h}$.

Fig. 5 X-ray diffraction patterns of mixed materials after electroless reduction with a calcium reductant in $\mathrm{CaCl}_{2}$ molten salt at $1173 \mathrm{~K}$ for $1 \mathrm{~h}$. The mixed materials consisted of titanium and zirconium oxides with a composition of $\mathrm{TiO}_{2}-70 \mathrm{at} \% \mathrm{ZrO}_{2}$.

Fig. 6 Change in the residual oxygen content of reduced materials, $\mathrm{C}_{0}$, with electroless reduction time, $t$. Electroless reduction was carried out with the calcium reductant of $\mathrm{e}=$ $200 \%$ at $1173 \mathrm{~K}$.

Fig. 7 SEM images of the reduced materials by a calcium reductant with $e=200 \%$ for a) $1 \mathrm{~h}, \mathrm{~b}) 2 \mathrm{~h}, \mathrm{c}) 4 \mathrm{~h}$, and d) $20 \mathrm{~h}$ at $1173 \mathrm{~K}$.

Fig. 8 SEM images of vertical cross sections of the Ti-Zr alloy reduced by electroless reduction with $\mathrm{e}=200 \%$ for $2 \mathrm{~h}$ at a) low and $\mathrm{b}$ ) high magnifications.

Fig. 9 EPMA-determined distributions of a) titanium and b) zirconium in a cross-section of the Ti-Zr alloy reduced by electroless reduction with e $=200 \%$ for $2 \mathrm{~h}$. The scales to the right indicate the relative intensities of titanium and zirconium, respectively. 
Fig. 10 X-ray diffraction patterns of mixed materials a) before and b) after immersion in $\mathrm{CaCl}_{2}$ molten salt without a calcium reductant at $1173 \mathrm{~K}$ for $2 \mathrm{~h}$. 


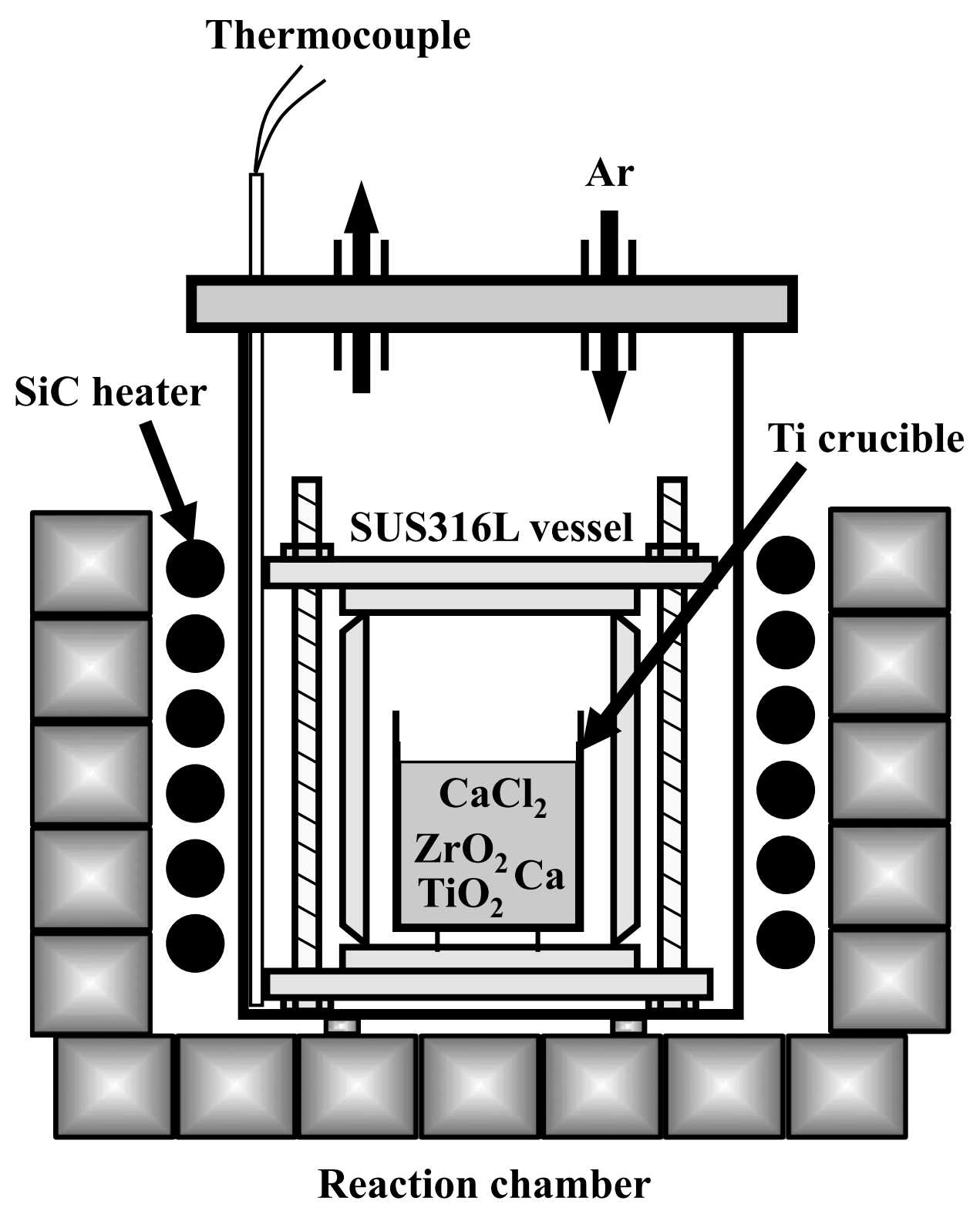

Fig. 1 


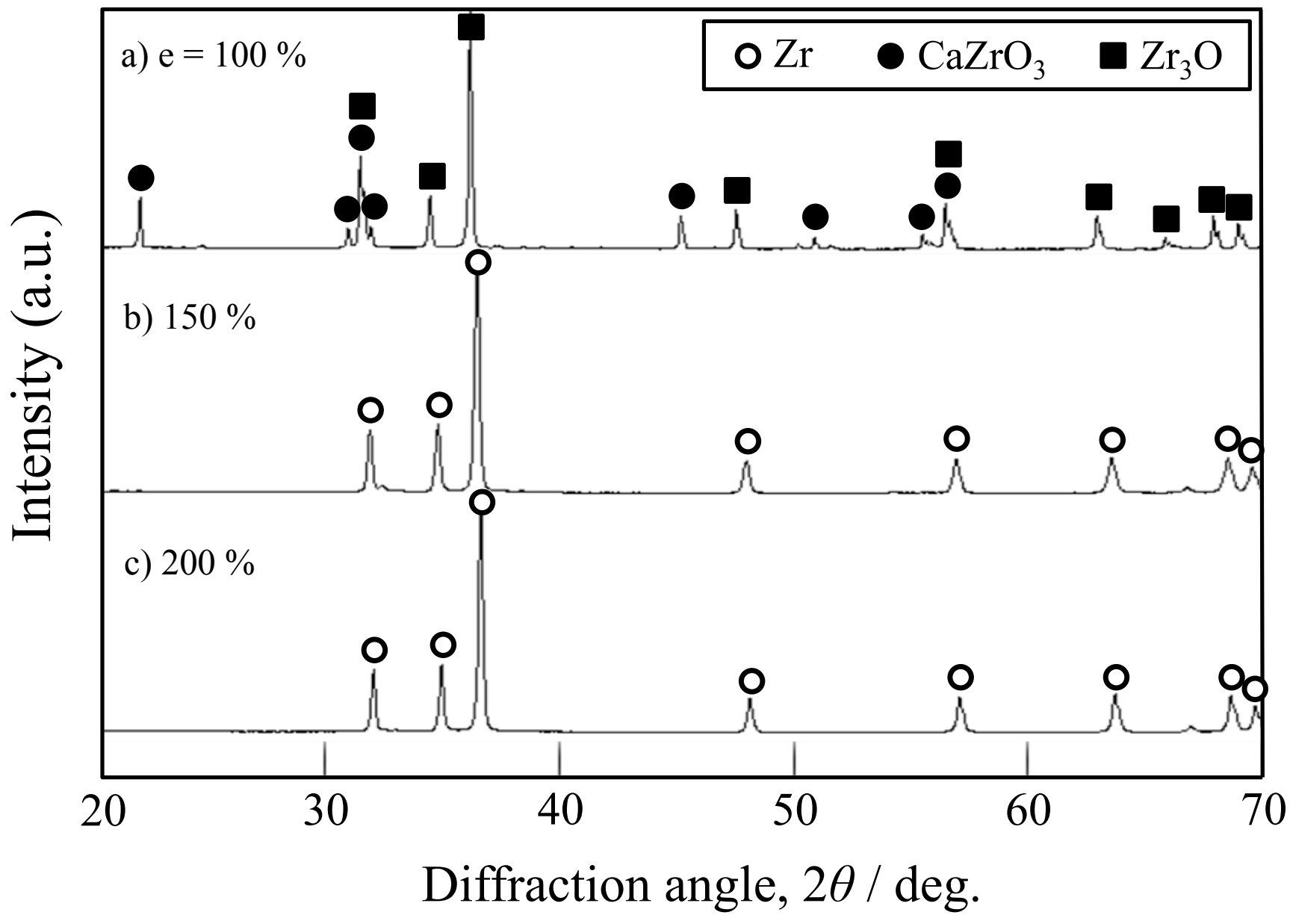

Fig. 2 
a) $\mathrm{ZrO}_{2}$ particles

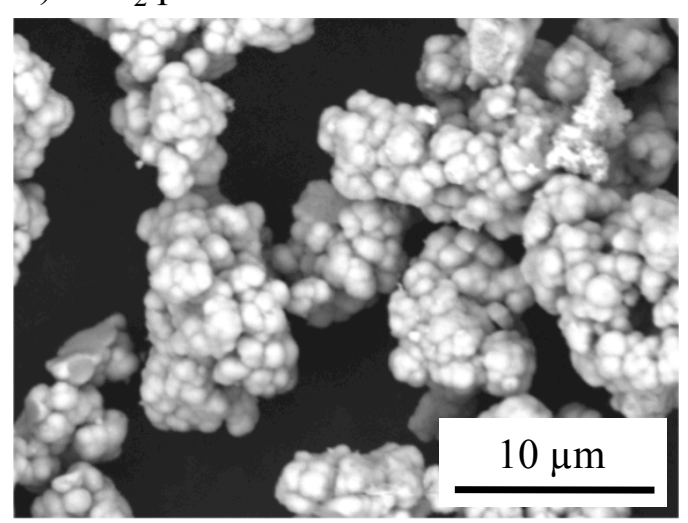

c) e $=150 \%$

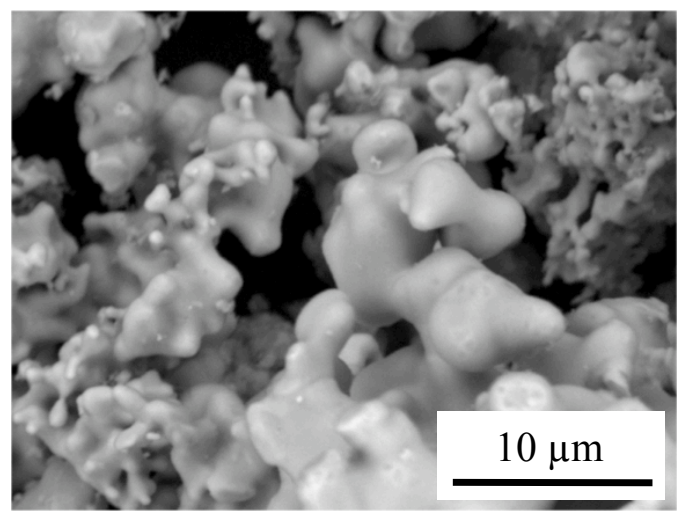

b) $\mathrm{e}=100 \%$

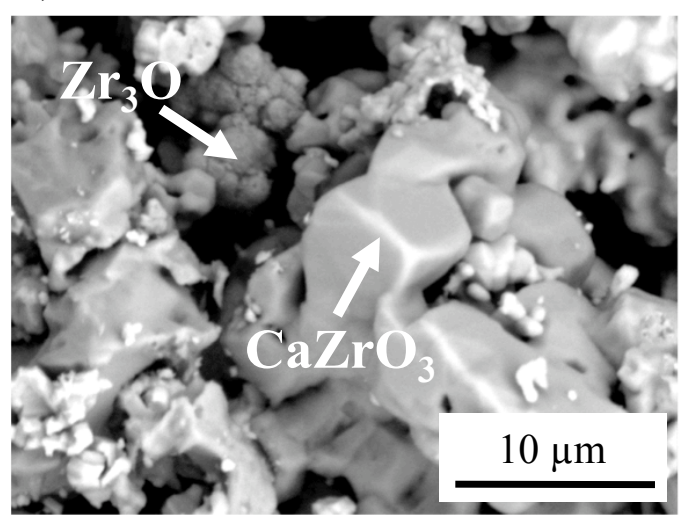

d) $\mathrm{e}=200 \%$

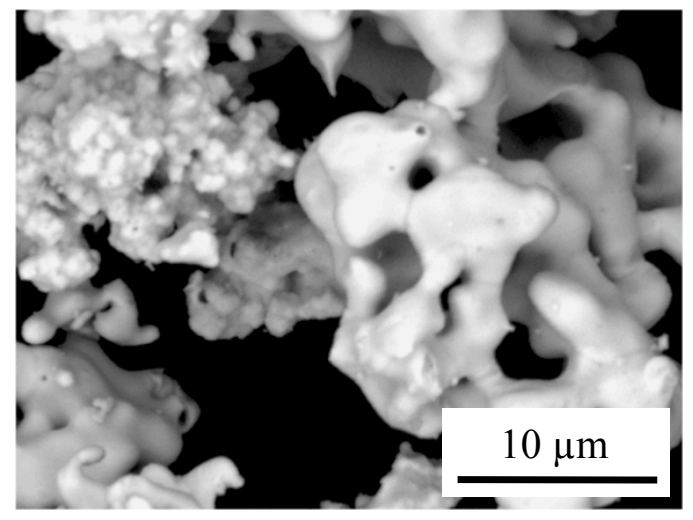

Fig. 3 


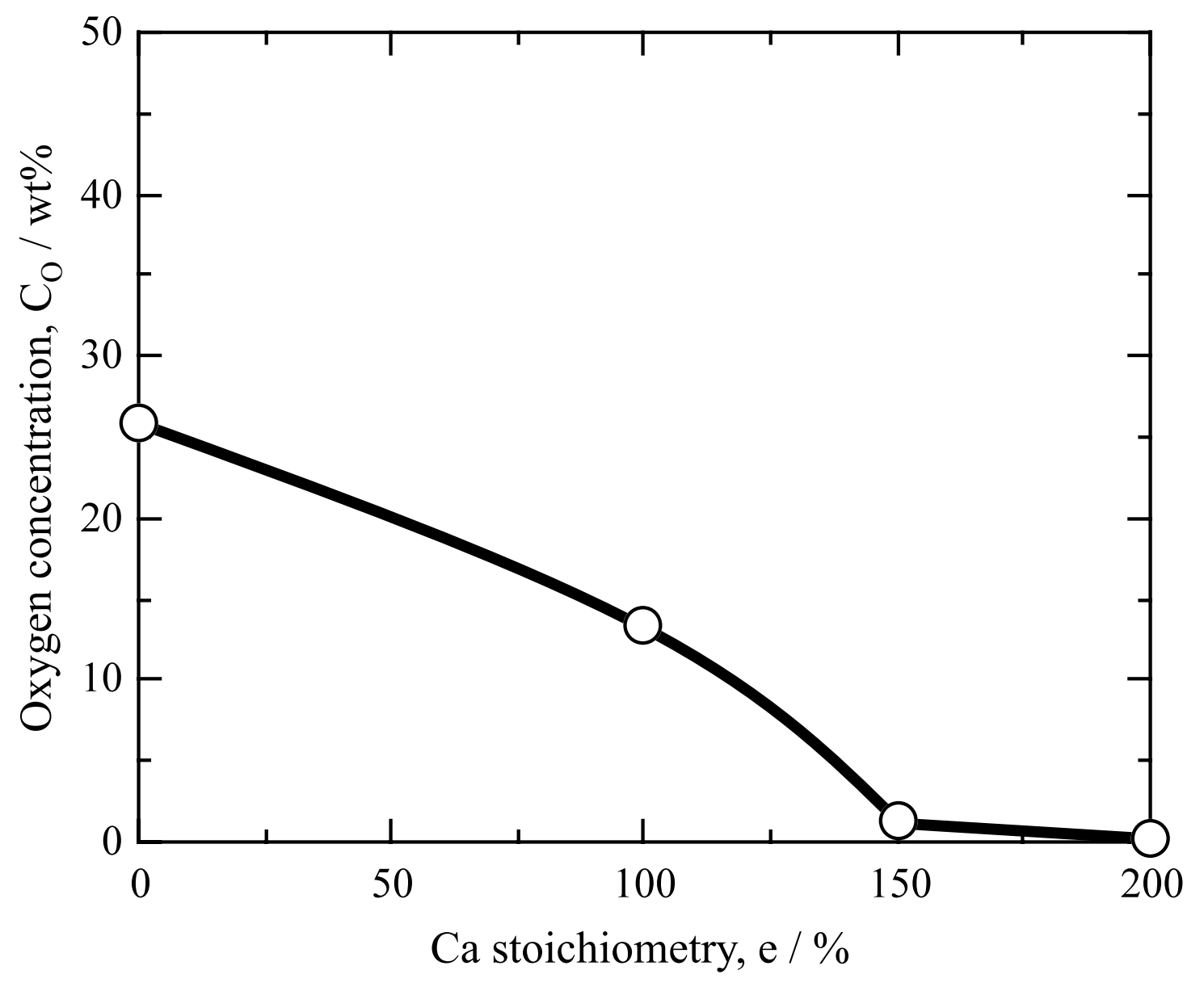

Fig. 4 


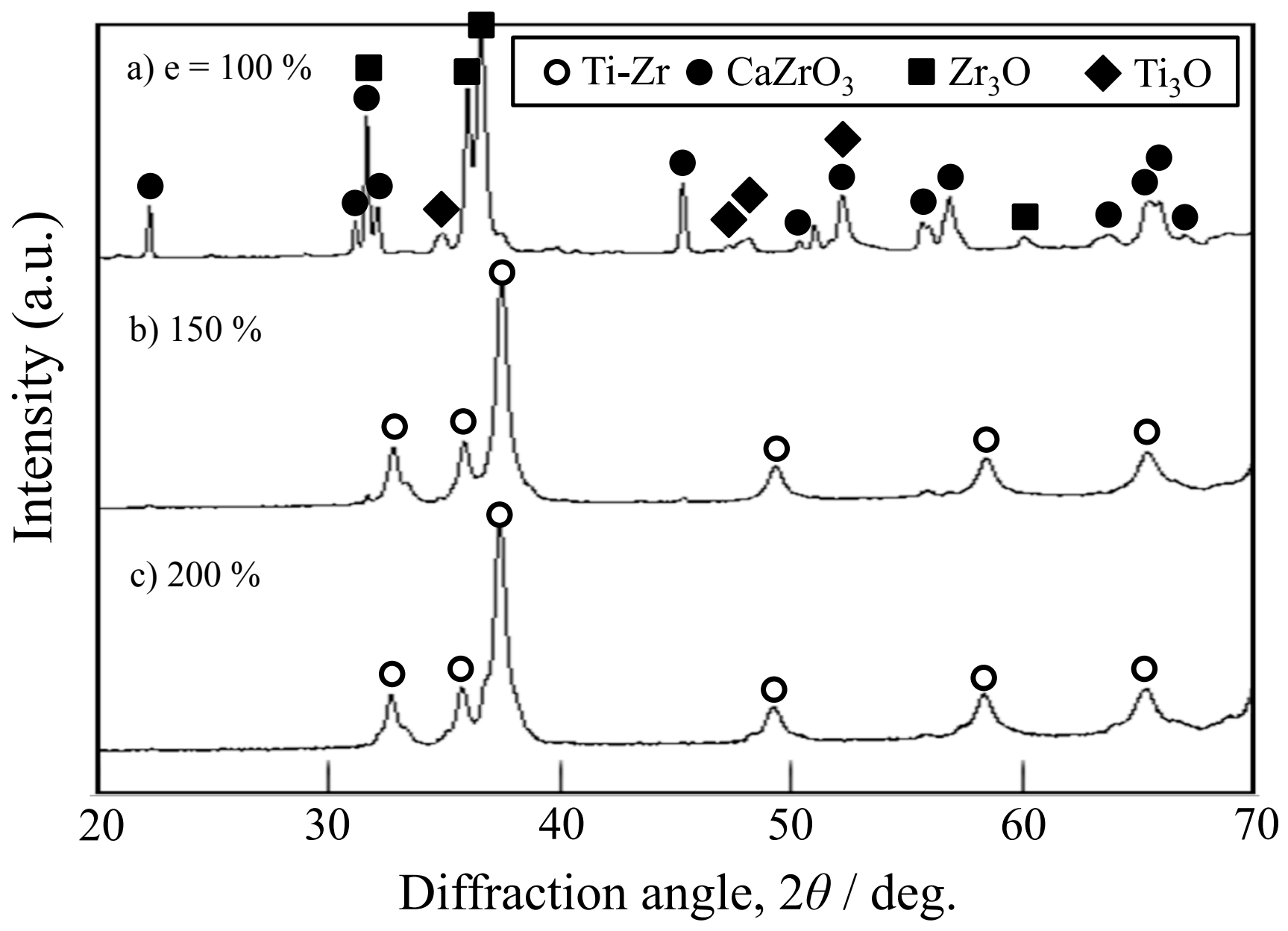

Fig. 5 


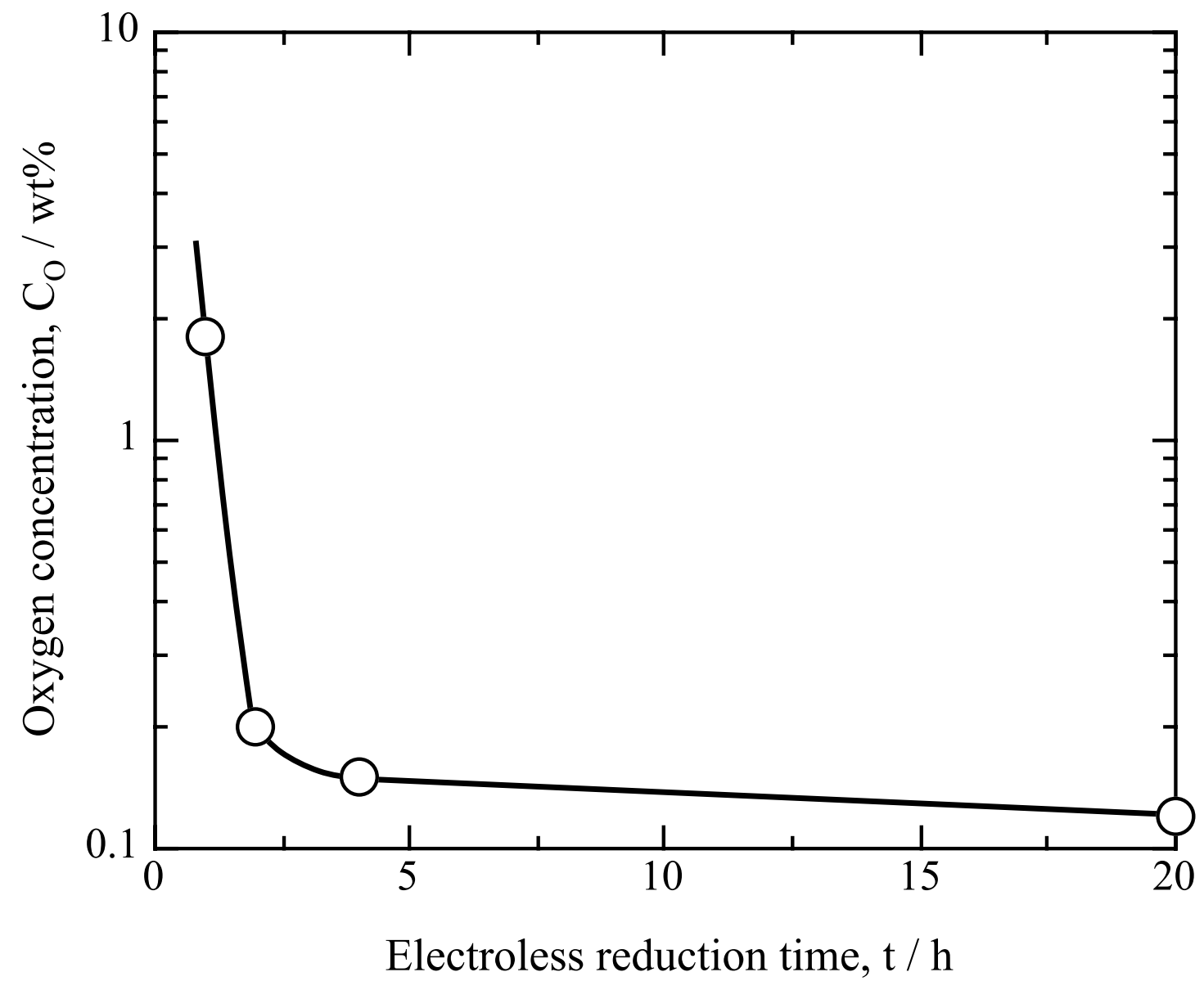

Fig. 6 
a) $t=1 \mathrm{~h}$

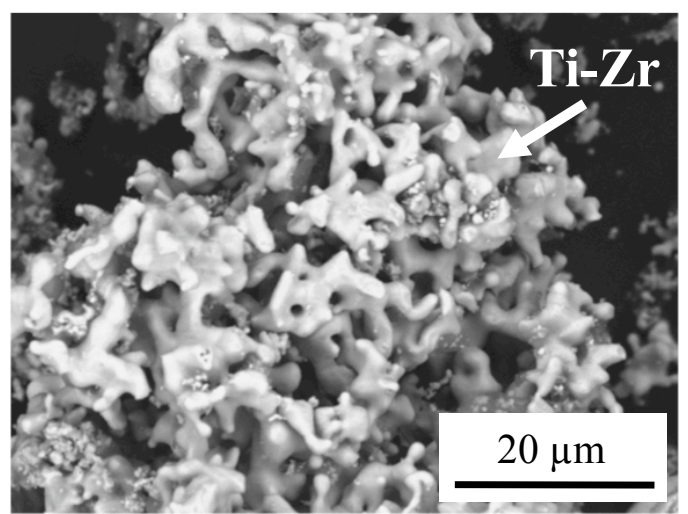

c) $t=4 \mathrm{~h}$

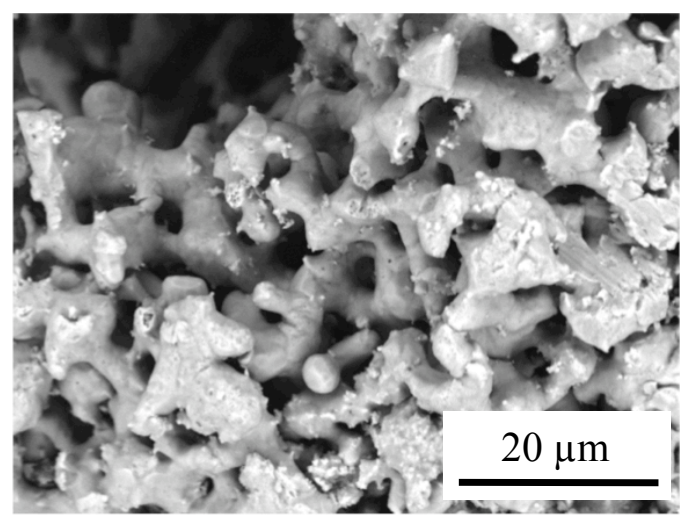

b) $t=2 h$

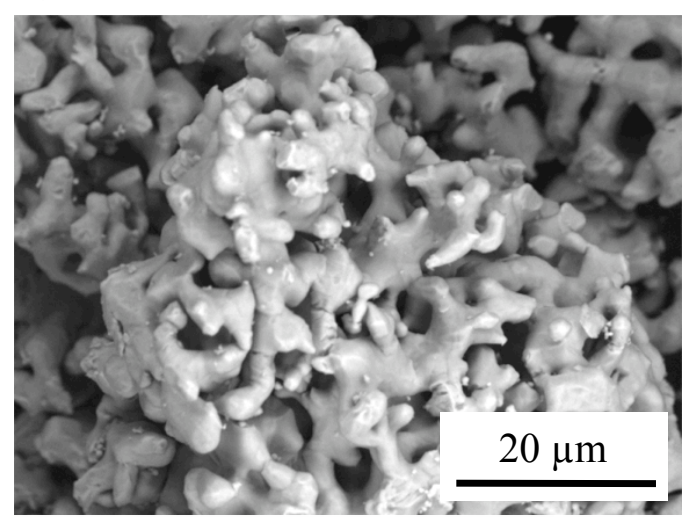

d) $t=20 \mathrm{~h}$

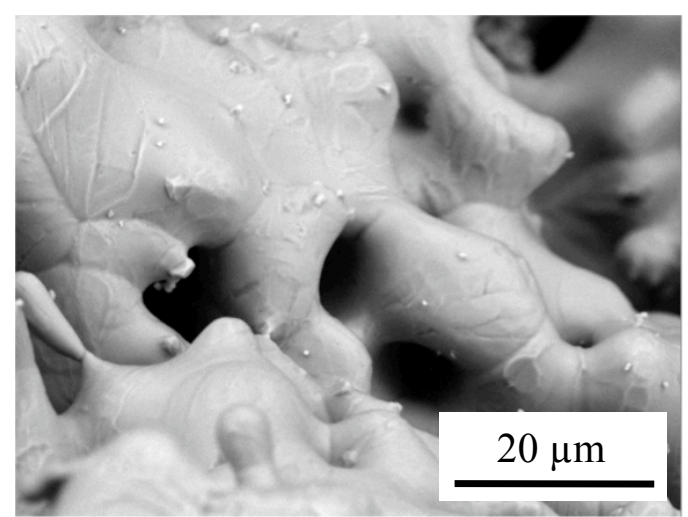

Fig. 7 
a)

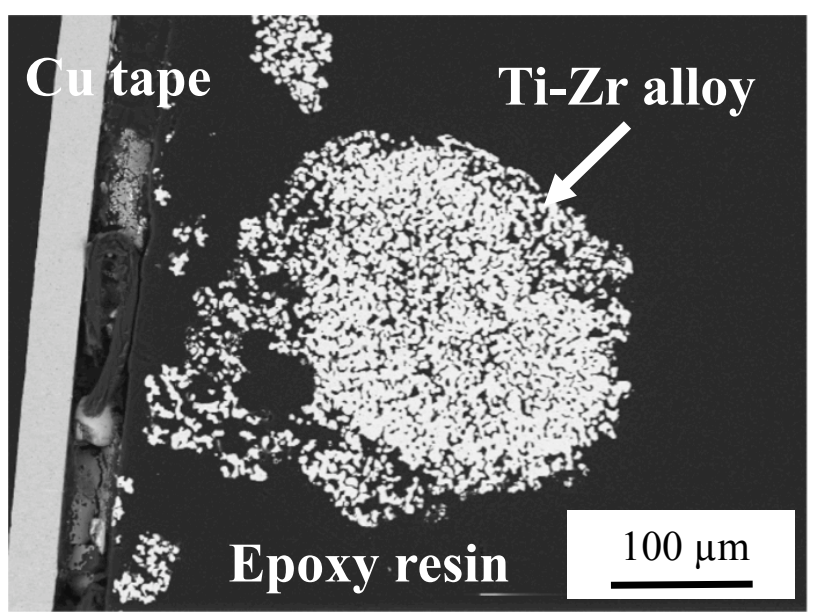

b)

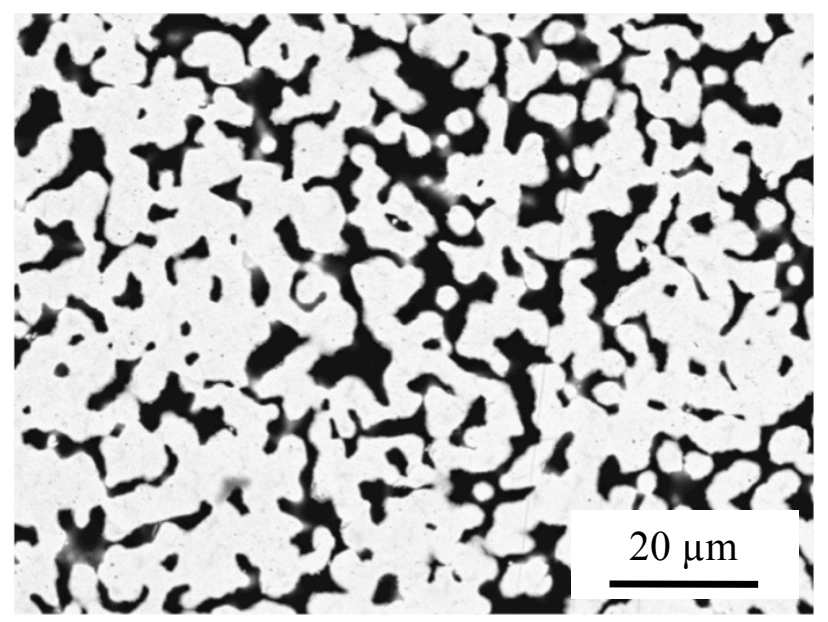

Fig. 8 
a) $\mathrm{Ti}$
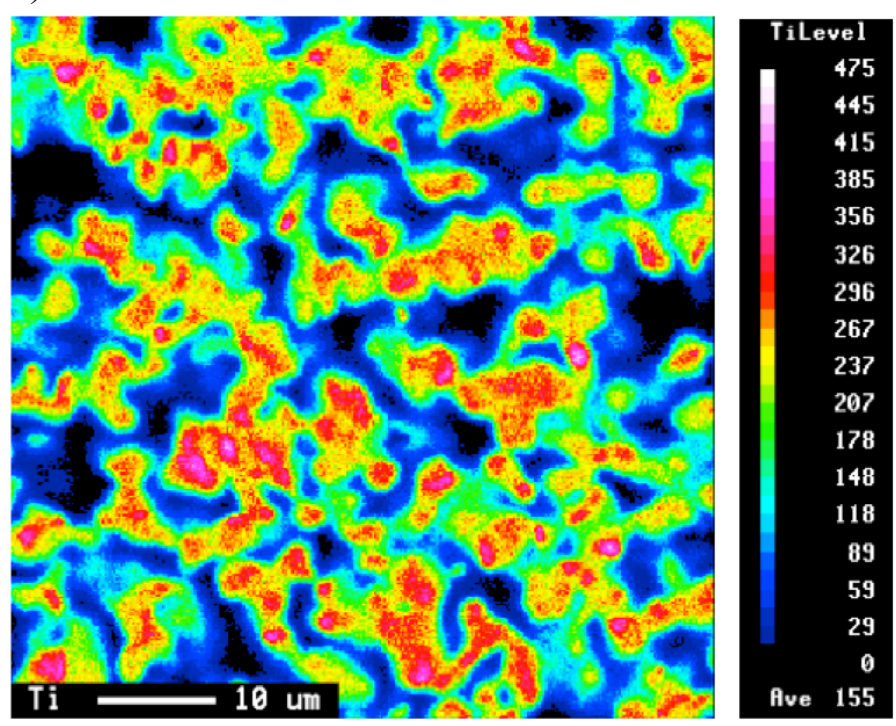

b) $\mathrm{Zr}$
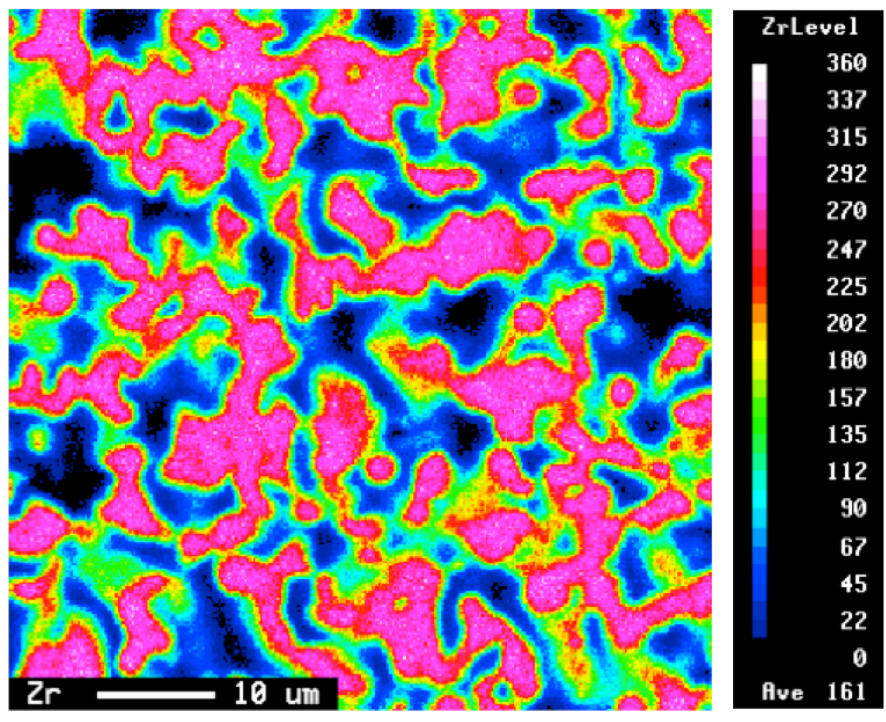

Fig. 9 


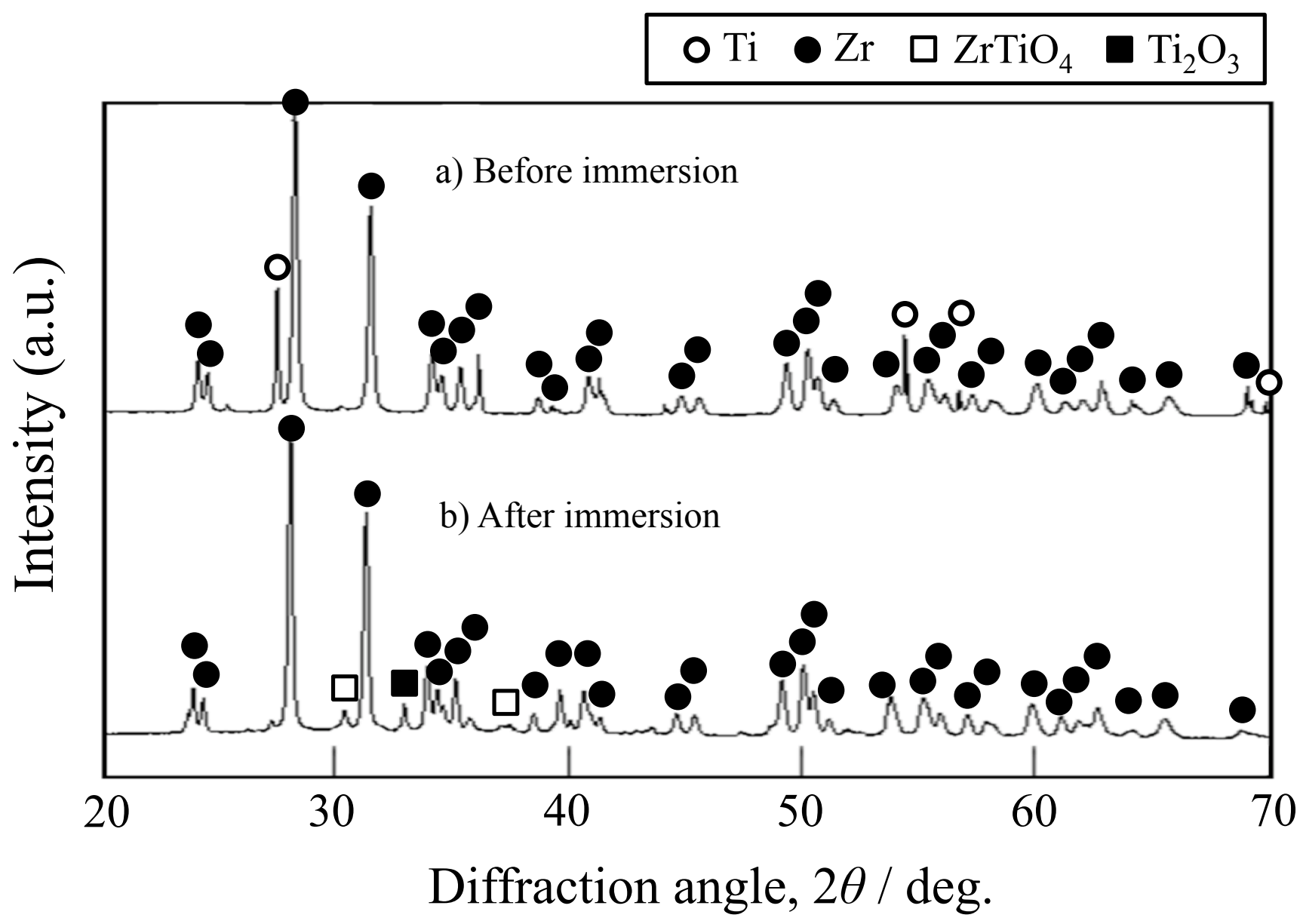

Fig. 10 